\title{
Silicon-Based Technology for Ligand-Receptor Molecular Identification
}

\author{
Annalisa Lamberti, ${ }^{1}$ Carmen Sanges, ${ }^{1}$ Nunzia Migliaccio, ${ }^{1}$ Luca De Stefano, ${ }^{2}$ Ilaria Rea, ${ }^{2}$ \\ Emanuele Orabona, ${ }^{2}$ Giuseppe Scala, ${ }^{3}$ Ivo Rendina, ${ }^{2}$ and Paolo Arcari ${ }^{1,4}$ \\ ${ }^{1}$ Department of Biochemistry and Medical Biotechnologies, University of Naples "Federico II", 80131 Naples, Italy \\ ${ }^{2}$ Institute for Microelectronics and Microsystems, Unit of Naples, National Council of Research, 80131 Naples, Italy \\ ${ }^{3}$ Department of Clinical and Experimental Medicine, University of "Magna Graecia", 88100 Catanzaro, Italy \\ ${ }^{4}$ CEINGE Advanced Biotechnology s.c.a.r.l, 80145 Naples, Italy \\ Correspondence should be addressed to Paolo Arcari, arcari@unina.it
}

Received 23 June 2011; Accepted 4 October 2011

Academic Editor: Ali Hussain Reshak

Copyright ( $(2012$ Annalisa Lamberti et al. This is an open access article distributed under the Creative Commons Attribution License, which permits unrestricted use, distribution, and reproduction in any medium, provided the original work is properly cited.

\begin{abstract}
One of the most important goals in the fields of biology and medicine is the possibility to dispose of efficient tools for the characterization of the extraordinary complexity of ligand-receptor interactions. To approach this theme, we explored the use of crystalline silicon ( $\mathrm{cSi}$ ) technology for the realization of a biotechnological device in which the ligand-receptor interactions are revealed by means of optical measurements. Here, we describe a chemical procedure for the functionalization of microwell etched on silicon wafers, and the subsequent anchoring of biological molecules like an antibody anti-A20 murine lymphoma cell line. The optical analysis of the interaction on the biochips between the bound biomolecule and their corresponding ligand indicated that the functionalized $\mathrm{cSi}$ is suitable for this application.
\end{abstract}

\section{Introduction}

Circulating tumor cells (CTCs) are emerging as a powerful prognostic and predictive biomarker in several types of cancer, including breast, colon, and prostate. However, studies of CTCs in metastasis and further development of CTCs as a biomarker in cancer have been hampered by the low concentration of CTCs in peripheral blood and by the inherent difficulties to recover CTCs from blood of patients. For this reason, it is compelling to implement novel devices and procedures to improve isolation rate and in vitro expansion of CTCs. Moreover, the extraordinary complexity of ligand-receptor interaction limits our knowledge of the molecular mechanisms of tumorigenesis and is a major obstacle in developing cancer-specific therapeutic agents. Pioneer studies of protein complexes have revealed that a given protein can physically associate to tens $(>200)$ of different proteins [1]. In the case of eukaryotic cells, 20,000 proteins or more may establish an extraordinary large number of functional interactions with cell receptors, making unrealistic a systematic approach where each ligand-receptor interaction is studied as a single network. To overcome these hurdles, we recently dedicated to a comprehensive analysis of ligand-receptor interactions in mammalian cells $[2,3]$ developing a novel biochip based on the chemical and optical properties of porous silicon [4] where the ligand-receptor interaction is transduced, at high levels of specificity and sensitivity, in an optical signal generated by change of pSI refractive index [5-7]. Here, we propose to develop a device based on crystalline silicon that combines analytic and preparative properties to improve speed and efficiency of isolation of CTCs from blood of patients affected by cancer. This will lead to the development of basic diagnostic kits that will be of help in the diagnosis of cancer and/or to the discovery of novel markers of pharmaceutical resistance as well as the identification of new target agents for treatment of cancer. The strategy includes the chemical functionalization of the silicon surface by using bifunctional linker molecules; the anchoring to the functionalized surface of specific antibodies; the assay of the biochip activity by 


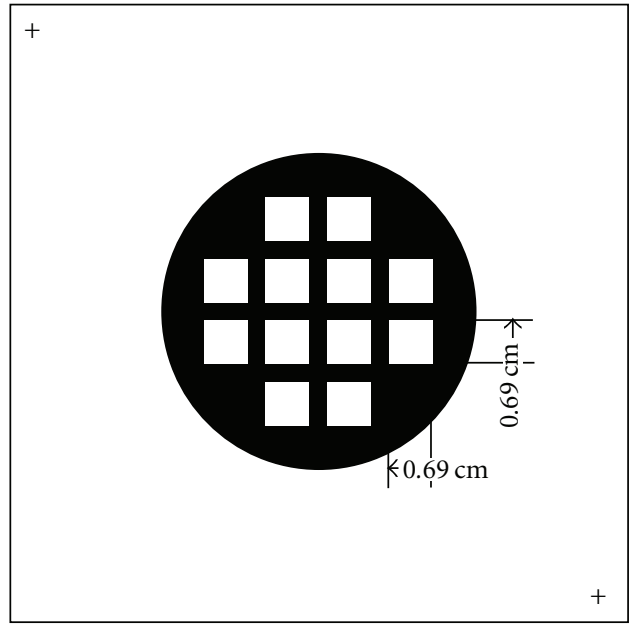

(a)

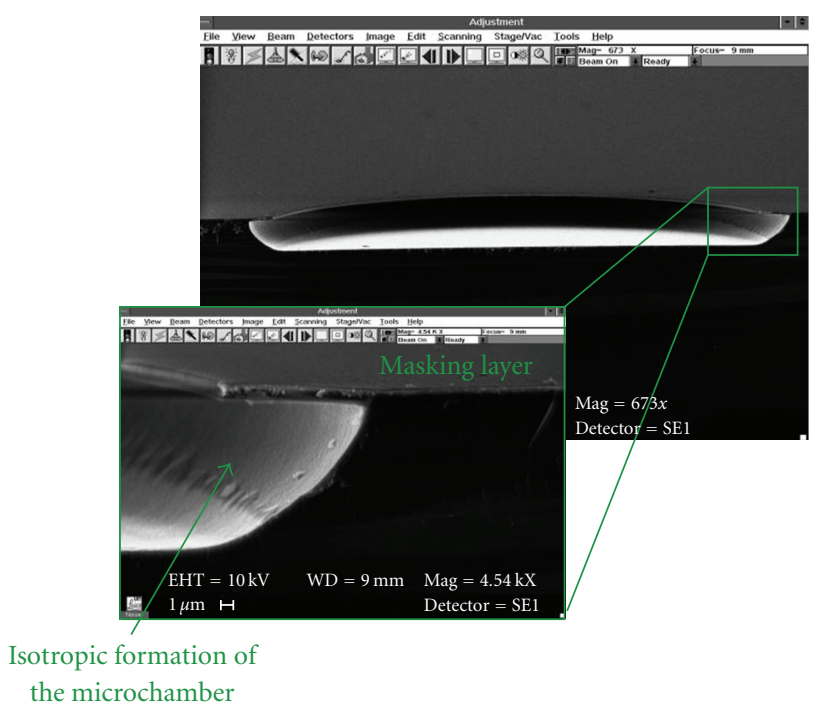

(b)

FIgure 1: Microwells wafer images. (a) 12 microwells photolithographic mask. (b) SEM image of a microwell with the enlargement showing the isotropic formation.

evaluating its ability to reveal the corresponding antibodyligand interaction.

\section{Experimental}

Silicon microwell array preparation. A silicon nitride film was obtained by plasma enhanced chemical vapor deposition on $\mathrm{p}^{+}$-silicon wafer, $\langle 100\rangle$ oriented; $400 \mu \mathrm{m}$ thick. A standard photolithographic process to pattern the silicon nitride film was used; the etching of the silicon nitride was performed by (reactive ion etching) RIE process in $\mathrm{CHF}_{3} / \mathrm{O}_{2}$ atmosphere followed by local electrochemical etching of silicon in a hydrofluoric acid-water solution $(50: 50, \mathrm{v} / \mathrm{v})$, photoresist removal by acetone, and anisotropic treatment in $\mathrm{KOH}$ $\left(\mathrm{KOH} / \mathrm{H}_{2} \mathrm{O}, 1: 2, \mathrm{w} / \mathrm{w}\right.$ ) of crystalline silicon (for microwell formation) for 120 minutes at $80^{\circ} \mathrm{C}$ under stirring. Removal

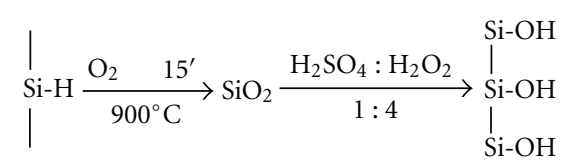

(a)<smiles>CCO[Si](CCCN)(OCC)O[SiH2][AsH2]</smiles>

(b)<smiles>CCO[Si](CCNC(=O)CCCC(N)=O)(OC)O[Si]</smiles>

(c)

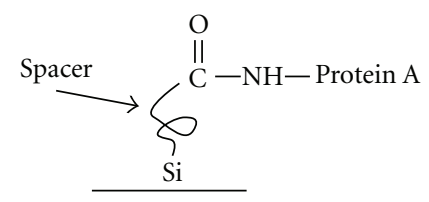

(d)

FIGURE 2: Functionalization steps of the crystalline silicon. (a) Oxidation and activation of $-\mathrm{OH}$ groups. (b) Reaction with bifunctional GA linker. (c) Binding of protein A to GA. (d) Functionalized microwell ready for the binding to IgG.

TABLE 1: Ellipsometric measurements of the surface layer thickness after each reaction step.

\begin{tabular}{lcccc}
\hline \multirow{2}{*}{ Steps } & \multicolumn{5}{c}{ Sample thickness $(\mathrm{nm})$} \\
& 1 & 2 & 3 & 4 \\
\hline Oxide & $73.4 \pm 0.2$ & $72.4 \pm 0.2$ & $75.0 \pm 0.3$ & $75.8 \pm 0.4$ \\
APTES + GA & $2.1 \pm 0.2$ & $3.1 \pm 0.3$ & $3.1 \pm 0.3$ & $3.0 \pm 0.4$ \\
& & $0.67 \pm$ & $0.75 \pm 0.1$ & $0.68 \pm$ \\
Protein A & $0.85 \pm 0.1$ & 0.08 & 0.09 \\
Spectral & $500-1600$ & $500-1600$ & $500-1600$ & $500-1600$ \\
range & 0.45 & 0.43 & 0.47 & 0.54 \\
$\chi 2$ &
\end{tabular}

$1,2,3,4$ represents four random microwells of the wafer chosen for chemical and physical characterization.

of the silicon nitride was done in $\mathrm{HF} / \mathrm{H}_{2} \mathrm{O}(1: 10)$ for $20 \mathrm{sec}$. The quality of silicon nitride layer was checked by ellipsometry in order to evaluate the thickness, roughness, and refractive index. The silicon nitride resulted $410 \mathrm{~nm}$ thick with a roughness of about $5 \mathrm{~nm}$.

Microwell functionalization. The microwells were functionalized according the following procedure. Microwells were thermal oxidized in $\mathrm{O}_{2}$ atmosphere at $900^{\circ} \mathrm{C}$ for 15 minutes and subsequently treated in a piranha solution (sulphuric acid $/ \mathrm{H}_{2} \mathrm{O}_{2}, 4: 1$ ) at room temperature (RT) for 40 minutes in order to activate the formation of - $\mathrm{OH}$ groups on 


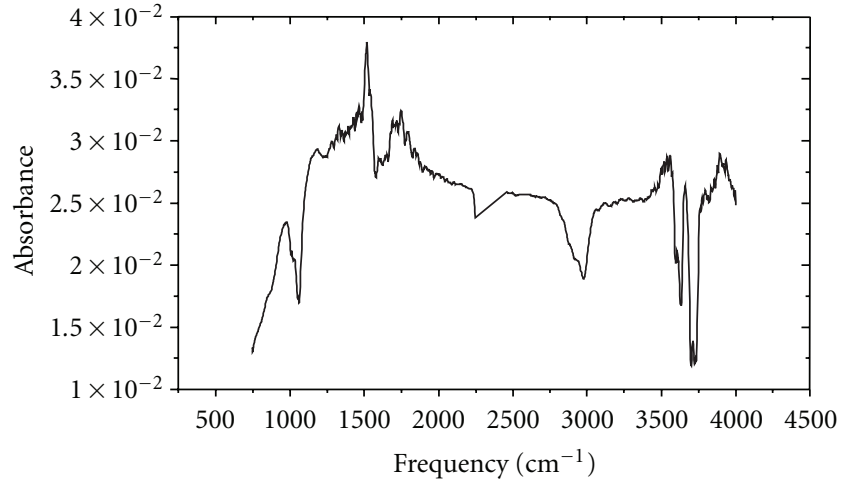

(a)

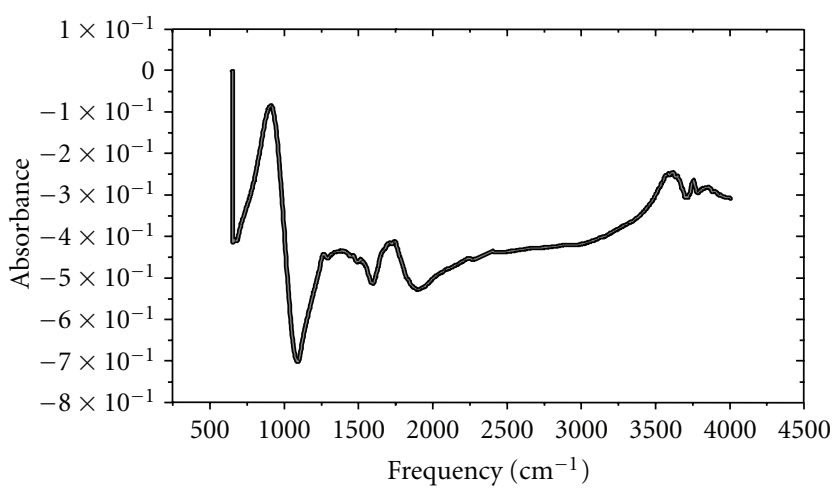

(c)

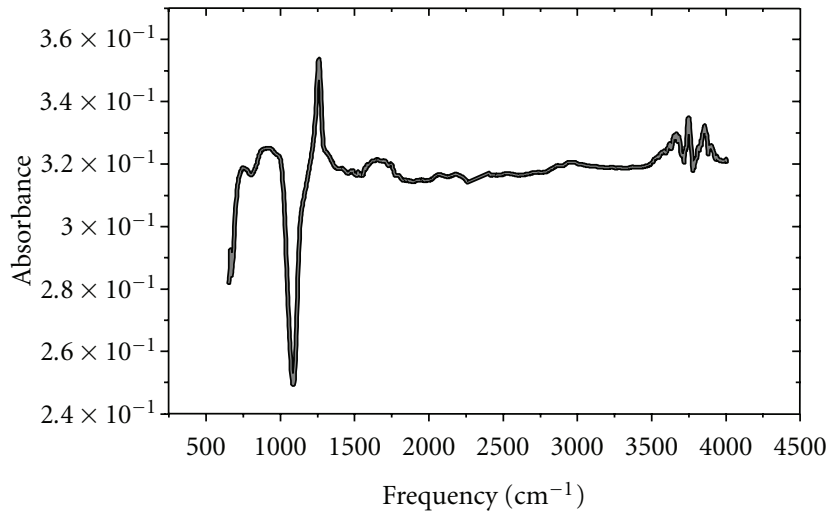

(e)

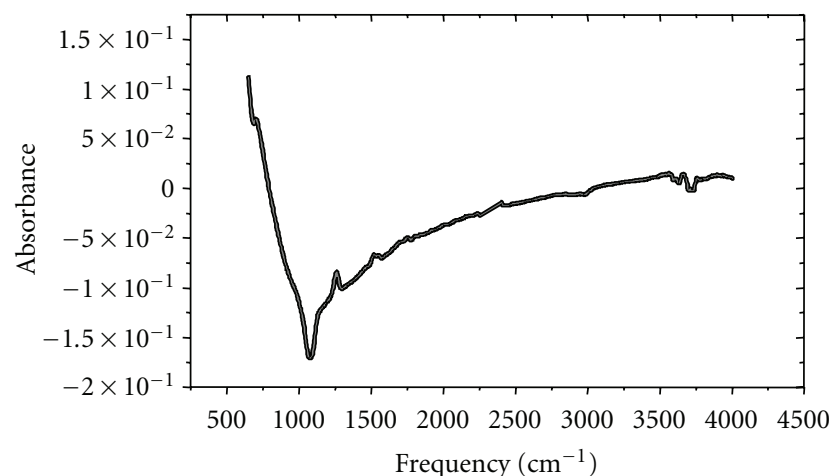

(b)

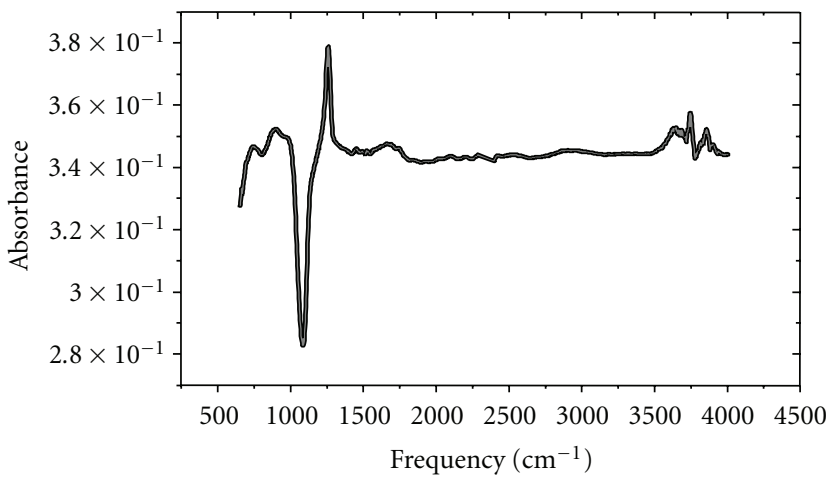

(d)

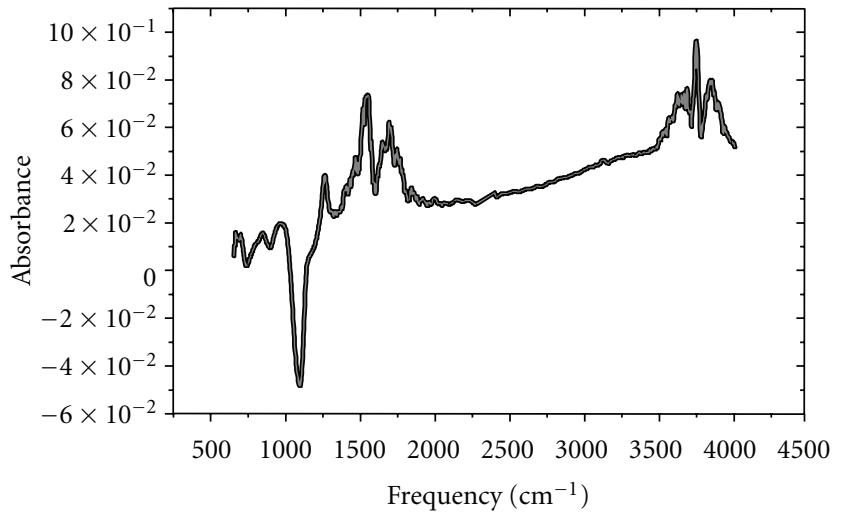

(f)

FIGURE 3: FT-IR spectra of the crystalline silicon (cSi) wafers after the functionalization steps. (a) cSi. (b) cSi after thermal oxidation. (c) cSi after APTES. (d) cSi after GA. (e) cSi after PA. (f) cSi after IgG.

the wafer surface. After extensive washes with distilled water and drying under $\mathrm{N}_{2}$, wafers were treated with a solution of 5\% APTES, (3-Aminopropyl) triethoxysilane (Sigma) in toluene for 30 minutes at RT, washed with toluene twice, curing on heater at $100^{\circ} \mathrm{C}$ for 10 minutes, and washed again with toluene twice. The wafers were then treated at RT for 30 minutes with a glutaraldehyde (GA) in $20 \mathrm{mM}$ HEPES (4(2-hydroxyethyl)-1-piperazineethanesulfonic acid), $\mathrm{pH}$ 7.5, and washed three times $(3 \times 5$ minutes $)$ in 20 mM HEPES, $\mathrm{pH}$ 7.5. Subsequently, the microwells were incubated at $4^{\circ} \mathrm{C}$ overnight in the presence of protein A (PA) $(2 \mathrm{mg} / \mathrm{mL}$, final concentration) in $20 \mathrm{mM}$ HEPES, $\mathrm{pH} 8.0(10 \mu \mathrm{L}$ of
PA solution for each well). Finally, after three washes of the microwells at RT with $20 \mathrm{mM}$ HEPES, pH $8.0(3 \times 5$ minutes) the devices were incubated overnight at $4^{\circ} \mathrm{C}$ with an antibody anti-IgG $6.6 \mu \mathrm{M}$ in $1 \mathrm{x}$ phosphate buffer saline (PBS). Lastly, after three washes $(3 \times 5$ minutes $)$ at $\mathrm{RT}$, the microwells were ready for experimental tests.

\section{Results and Discussion}

Figure 1 shows the photolithographic mask of 12 crystalline silicon microwells. The scanning electron microscopy (SEM) image of the microwell showed that microwells were about 
TABLE 2: Frequencies $\left(\mathrm{cm}^{-1}\right)$ of major infrared bands observed in wafer samples and peak assignment.

\begin{tabular}{|c|c|c|c|c|c|c|}
\hline \multirow[b]{2}{*}{ A } & \multicolumn{4}{|c|}{ Frequency $\mathrm{cm}^{-1}$} & \multirow[b]{2}{*}{$\mathrm{F}$} & \multirow[t]{2}{*}{ Predicted peak } \\
\hline & $\mathrm{B}$ & $\mathrm{C}$ & $\mathrm{D}$ & $\mathrm{E}$ & & \\
\hline 一 & 1127 & - & - & - & - & Si-O str \\
\hline 一 & - & 1250 & 1250 & 1258 & 1258 & $\mathrm{Si}-\mathrm{O}-\mathrm{C}$ as str \\
\hline 一 & - & $1295-1305$ & - & - & - & $-(\mathrm{CH} 2)-\mathrm{str}$ \\
\hline - & - & $1445-1475$ & - & - & - & -O-CH2-str \\
\hline - & - & - & - & - & 1531 & Amide II \\
\hline - & - & & - & 1635 & 1642 & $\mathrm{C}=\mathrm{O}$ str \\
\hline - & - & 1650 & - & - & - & $\begin{array}{l}\text { Saturated primary } \\
\text { ammine (-NH2 def) }\end{array}$ \\
\hline - & - & - & - & $1650-1680$ & $1638-1687$ & Amide I C=O str \\
\hline - & - & - & - & $1685-1705$ & 1774 & $\mathrm{C}=\mathrm{O}$ str \\
\hline - & - & - & - & - & 3121 & $\mathrm{~N}-\mathrm{H}$ str \\
\hline - & - & $3250-3677$ & - & - & - & $\begin{array}{c}\text { Primary ammine } \\
-\mathrm{NH} 2 \mathrm{str}\end{array}$ \\
\hline
\end{tabular}

A, B, C, D, E, and F are referred to the samples as indicated in Figure 2.
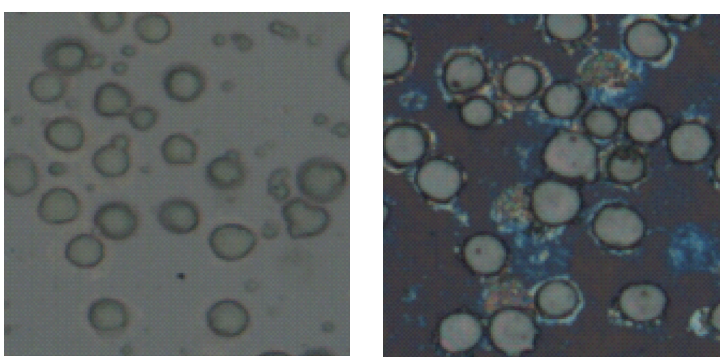

$100 \mu \mathrm{m}$

(a)

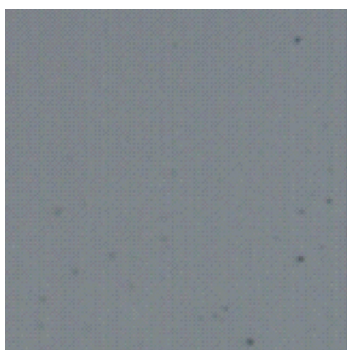

(b)

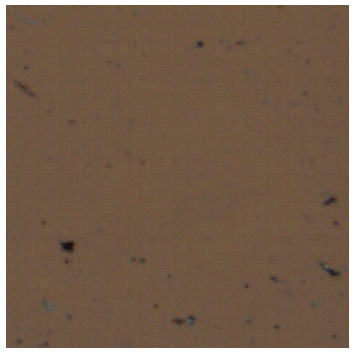

(c)

(d)

FIgure 4: Binding of A20 cells to the functionalized silicon wafer. Images from optical microscope (20x enlargement) of the biochip functionalized with antibody anti-IgG $(6,8 \mu \mathrm{M})$ and then incubated with A20 cells before washes (a) and after washes (b). Optical image after washes of the biochip functionalized with anti-IgG and incubated with CB1 cells (c). Optical image after washes of the biochip lacking anti-IgG and incubated with A20 cells (d).

$5.7 \mu \mathrm{l}(0.69 \mathrm{~cm} \times 0.69 \mathrm{~cm} \times 120 \mu \mathrm{m})$. Moreover, the SEM image enlargements highlighted the isotropic formation of the microchamber. The microwells were functionalized according to the chemical reaction steps schematically reported in Figure 2. In order to check the efficiency of each reaction, we evaluated the presence of the chemical layer by ellipsometric measurements. As reported in Table 1, using a random sampling of 4 different wells, it was observed for all of them after each functionalization step almost the same chemical properties. This procedure was also followed by FT-IR spectromicroscopy performed with a Nicolet 5700 equipped with a microscope Continu $\mu \mathrm{m}$, settled with a $50 \times$ $50 \mu \mathrm{m}$ window, sensitivity 8 , and 200 acquisition/minute (Figure 3). The analyses of the FT-IR spectra led to the identification of several characteristic vibration bands that were coherent with the various functionalization steps. Table 2 reports a list of the major bands identified together to peak assignment.

We next explored the application of the functionalized biochip to function as possible array for the binding and identification of cell lines. As on experimental model, it was chosen a murine lymphoma cell line (A20) [8]. These cells express high levels of membrane IgG. For this purpose, antibody antimembrane immunoglobulin was bound to the functionalized biochip as previously described. The biochip was then incubated in the presence of A20 cells at a concentration of $5 \times 10^{6}$ cells $/ \mathrm{mL}$ in $1 \times$ PBS at RT for 2 hours. After several washes in $1 \mathrm{x}$ PBS, the wafers were analyzed under a light microscope (Leika DM6000M). As negative control, it was used a microwell that was incubated with a cell line not expressing membrane IgG (CB1) and a biochip lacking the antibody anti-IgG. As shown in Figure 4, the IgG-functionalized microwell was able to bind specifically the A20 cells (Figures 4(a) and 4(b)) whereas it did not recognize different cells (Figure 4(c)). In addition, A20 cells were not able to bind to the biochip lacking antibody antiIgG (Figure 4(d)).

\section{Conclusions}

In this experimental work, we explored the use of the crystalline silicon technology in order to construct a biochip 
that allows the identification of specific ligand-receptor interactions. The microfabricated biochips appear to be suitable to reveal specific bindings such as that between cell surface proteins (receptor) and corresponding specific antibody. The results obtained represent an encouraging starting point for the application of this specific technology to develop a lab-on-chip microarray system for the specific recognition circulating tumor cells (CTCs). Moreover, the versatility of the engineered biochip could be useful to reveal other several specific bindings such as that between an antibody and its ligand peptide. Furthermore, this biochip can be useful to find and characterize new specific receptor-ligand interactions through the screening of a recombinant phage library.

\section{Acknowledgment}

The work described was financed by MIUR (Rome), FIRB 2003, Contract no. RBLA033WJX_003.

\section{References}

[1] A. C. Gavin, M. Bösche, R. Krause et al., "Functional organization of the yeast proteome by systematic analysis of protein complexes," Nature, vol. 415, no. 6868, pp. 141-147, 2002.

[2] G. Scala, X. Chen, W. Liu et al., "Selection of HIV-specific immunogenic epitopes by screening random peptide libraries with HIV-1-positive sera," Journal of Immunology, vol. 162, no. 10, pp. 6155-6161, 1999.

[3] P. De Berardinis, R. Sartorius, C. Fanutti, R. N. Perham, G. Del Pozzo, and J. Guardiola, "Phage display of peptide epitopes from HIV-1 elicits strong cytolytic responses," Nature Biotechnology, vol. 18, no. 8, pp. 873-876, 2000.

[4] L. De Stefano, L. Moretti, A. Lamberti et al., "Optical sensors for vapors, liquids, and biological molecules based on porous silicon technology," IEEE Transactions on Nanotechnology, vol. 3, no. 1, pp. 49-54, 2004.

[5] L. De Stefano, L. Rotiroti, I. Rea et al., "Porous silicon-based optical biochips," Journal of Optics A, vol. 8, no. 7, pp. S540S544, 2006.

[6] L. De Stefano, P. Arcari, A. Lamberti et al., "DNA optical detection based on porous silicon technology: from biosensors to biochips," Sensors, vol. 7, no. 2, pp. 214-221, 2007.

[7] E. De Tommasi, L. De Stefano, I. Rea et al., "Porous silicon based resonant mirrors for biochemical sensing," Sensors, vol. 8, no. 10, pp. 6549-6556, 2008.

[8] L. H. Glimcher, K. J. Kim, I. Green, and W. E. Paul, "Ia antigenbearing $\mathrm{B}$ cell tumor lines can present protein antigen and alloantigen in a major histocompatibility complex-restricted fashion to antigen-reactive T cells," Journal of Experimental Medicine, vol. 155, no. 2, pp. 445-459, 1982. 

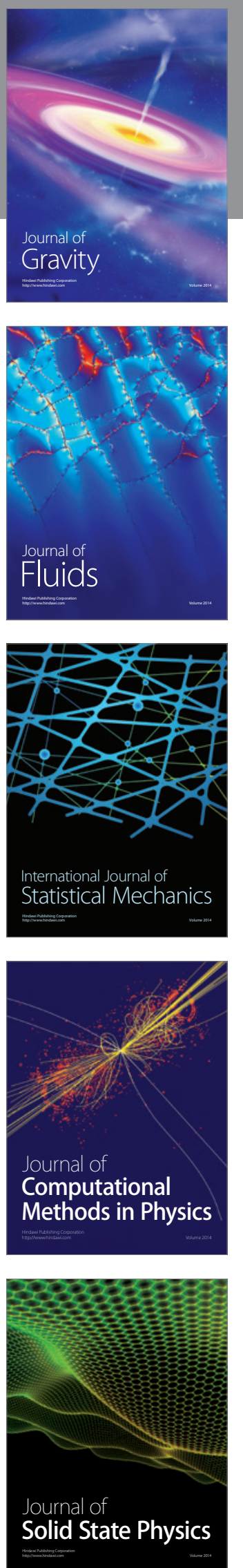

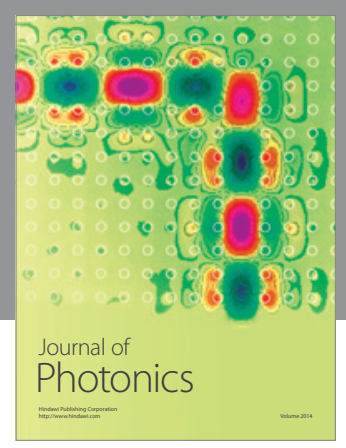

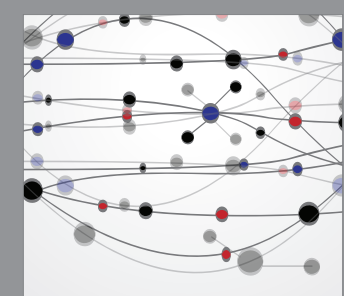

The Scientific World Journal
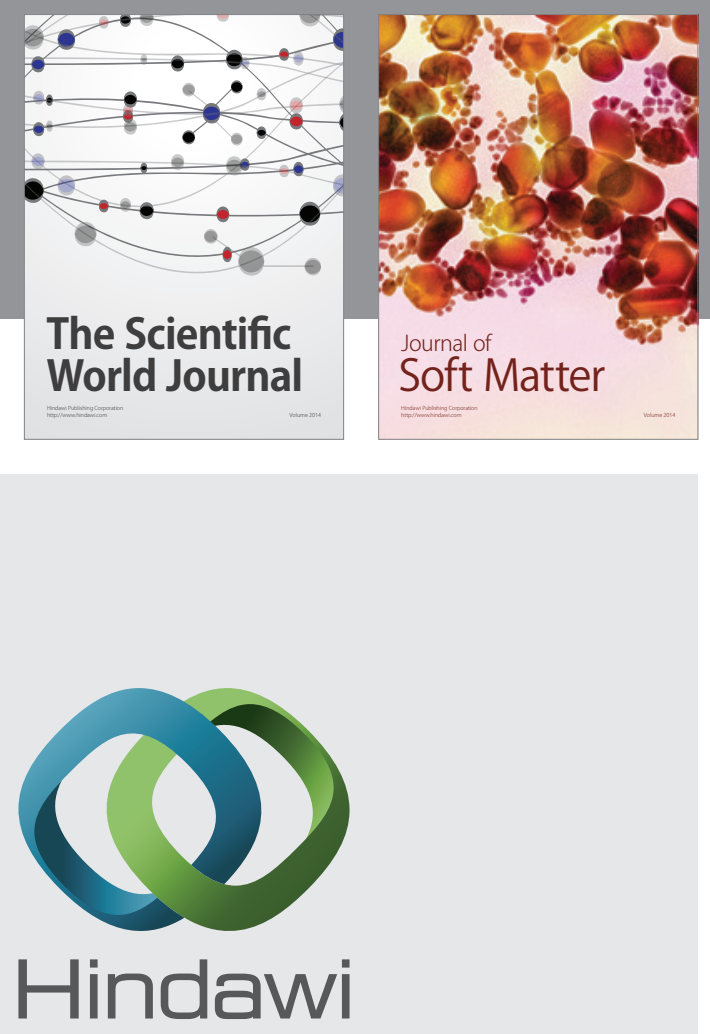

Submit your manuscripts at

http://www.hindawi.com
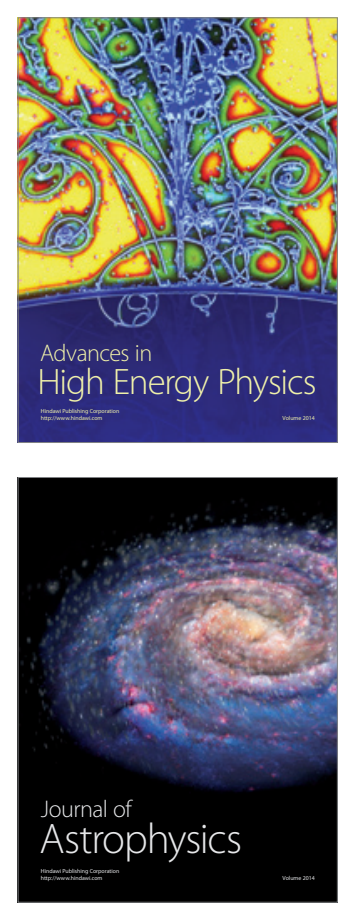
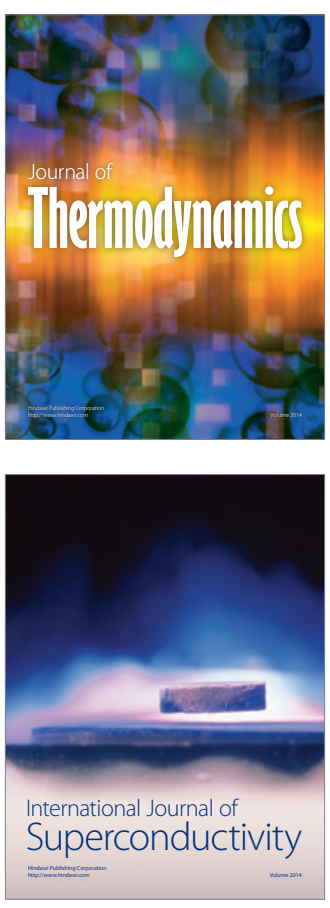
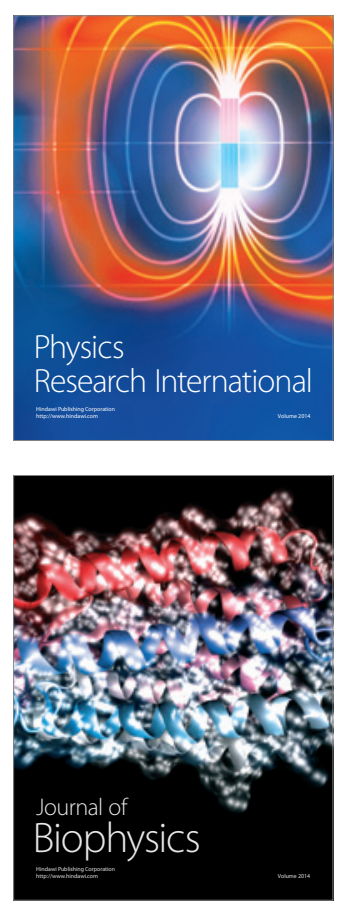
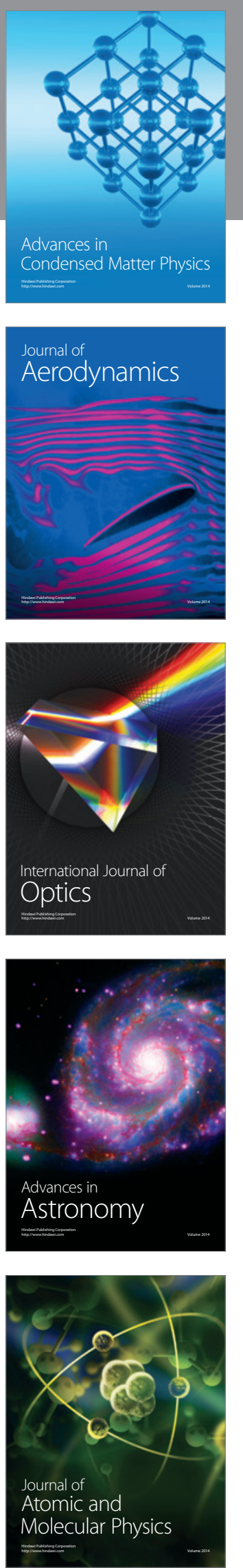